\title{
Evaluation of an association between plasma total homocysteine and schizophrenia by a Mendelian randomization analysis
}

\author{
Shusuke Numata ${ }^{1 *}$, Makoto Kinoshita ${ }^{1}$, Atsushi Tajima ${ }^{2,3}$, Akira Nishi ${ }^{1}$, Issei Imoto ${ }^{3}$ and Tetsuro Ohmori ${ }^{1}$
}

\begin{abstract}
Background: The results of meta-analyses conducted by previous association studies between total homocysteine and schizophrenia suggest that an elevated total homocysteine level is a risk factor for schizophrenia. However, observational studies have potential limitations, such as confounding and reverse causation. In the present study, we evaluated a causal relationship between plasma total homocysteine and schizophrenia by conducting a Mendelian randomization analysis.

Methods: We used the MTHFR C677T polymorphism as an instrumental variable, which affects the plasma total homocysteine levels. To calculate the risk estimate for the association of this single nucleotide polymorphism (SNP) with schizophrenia, we conducted a meta-analysis of case-control studies that comprise a total of 11,042 patients with schizophrenia and 14,557 control subjects. We obtained an estimate for the association of this SNP with the plasma total homocysteine levels from a meta-analysis of genome-wide association studies comprising 44,147 individuals.
\end{abstract}

Results: By combining these two estimates, we demonstrated a significant effect of the plasma total homocysteine on schizophrenia risk, representing an OR of $2.15\left(95 \% \mathrm{Cl}=1.39-3.32 ; \mathrm{p}=5.3 \times 10^{-4}\right)$ for schizophrenia per 1-SD increase in the natural log-transformed plasma total homocysteine levels.

Conclusions: We provided evidence of a causal relationship between the plasma total homocysteine and schizophrenia, and this result will add insight into the pathology and treatment of schizophrenia.

\section{Background}

Homocysteine is a key substance in the methionine cycle, which is involved in one-carbon methyl group-transfer metabolism. The methylenetetrahydrofolate reductase (MTHFR) C677T (rs1801133) polymorphism is a wellcharacterized genetic variant. C677T of the MTHFR gene results in amino-acid substitution (Ala222Val), and causes a reduction of enzyme activity and higher plasma total homocysteine levels [1]. The association of this variant with the plasma total homocysteine was confirmed by a recent meta-analysis of genome-wide association studies [2]. Previous meta-analyses of association studies between total homocysteine, which includes plasma and serum total

\footnotetext{
* Correspondence: shu-numata@umin.ac.jp

'Department of Psychiatry, Institute of Biomedical Sciences, Tokushima University Graduate School, 3-18-15, Kuramoto, Tokushima 770-8503, Japan Full list of author information is available at the end of the article
}

homocysteine, and schizophrenia suggest that an elevated total homocysteine level is a risk factor for schizophrenia $[3,4]$. However, observational studies have potential limitations, such as confounding, reverse causation, and selection bias. In fact, several findings of observational studies have been shown to be spurious causes by subsequent randomized controlled trials, such as hormone replacement therapy in coronary heart disease, $\beta$ carotene in lung cancer, and vitamin $\mathrm{E}$ and vitamin $\mathrm{C}$ in cardiovascular disease [5]. In addition to genetic variants [2], many determinants that affect plasma total homocysteine concentrations, including physiologic determinants, such as age and sex, lifestyle determinants, such as vitamin intake, smoking and coffee, and clinical conditions, such as folate deficiency and renal failure, have been reported [6]. Moreover, whether hyperhomocysteine itself causes schizophrenia or schizophrenia causes hyper-homocysteine has not been clarfied. For 
examples, the high prevalence of smoking and decreased folate levels in patients with schizophrenia have been reported [7-10], both of which are known to be associated with increased plasma total homocysteine concentrations.

Mendelian randomization analysis, which uses genetic variants as instrumental variables for exposures of interest, can overcome problems of confounding and reverse causality, and is a useful method for assessing causal relationships in epidemiological studies [11-16].

Mendelian randomization refers to the random allocation of alleles at the time of gamete formation. A specific genotype carried by a person results from two such randomized transmission, one from the paternally inherited allele and the other from the maternally allele. As a consequence of these randomizations, genotypes are not expected to be associated with known or unknown confounders for any outcome of interest, except those lying on the causal pathway between the genotype and the outcome. This allows analyzing the genotype-risks factor association (in this case, the genotype-the plasma total homocysteine) and the genotype-outcome association (in this case, the genotype-schizophrenia) in an unconfounded manner [13]. By combining the results of the genotype-risk factor association and the genotype-outcome association, one can get an estimate of the risk factor-outcome association (in this case, the plasma total homocysteineschizophrenia). In addition, genetic variants are equivalent to lifetime differences in risk factor (in this case, the plasma total homocysteine), and indicate the long term effects of risk factor on disease (in this case, schizophrenia). They therefore generate more realistic estimates of causal effects between risk factor and disease [5]. The Mendelian randomization approach has similar properties to the analysis of the intention to treat in randomized controlled trials $[5,17]$, and this approach has provided new insights into the pathology of several diseases, such as cardiovascular disease, diabetes, and Parkinson disease [18-26].

In this study, we evaluated a causal relationship between plasma total homocysteine and schizophrenia by conducting a Mendelian randomization analysis based on the MTHFR C677T polymorphism as an instrumental variable.

\section{Methods}

\section{The estimate for gene-schizophrenia association}

The risk estimate for the gene-schizophrenia association of the $\mathrm{T}$ allele of the MTHFR C677T polymorphism (OR $\mathrm{scz} /$ per T-allele) was evaluated by conducting a meta-analysis of case-control studies with the random-effect model by 'metafor', an R package. Eligible studies were identified using SZGene [27] and the PubMed search engine with the terms "Methylenetetrahydrofolate reductase" or "MTHFR" or "schizophrenia". We also conducted an additional manual search of reference lists and review articles.
Studies meeting the following criteria were included for meta-analysis: (1) performed a case-control study (i.e., schizophrenia versus control), (2) provided data on genotype frequencies, and (3) was published in the English language. The two reviewers (Kinoshita $M$ and Nishi A) selected the articles independently according to the above inclusion criteria, and then discussed the articles until they reached a consensus on every study used for the metaanalysis. Heterogeneity was assessed using the $\mathrm{I}^{2}$ statistic, and publication bias was assessed using funnel plots and a regression test [28]. OR and $95 \%$ confidence intervals (CI) were calculated by 'metafor', an R package. Finally, we used 36 case-control studies from 32 papers for a total of 11,042 patients with schizophrenia and 14,557 control subjects [4, 29-59] based on a Preferred Reporting Items for Systematic Review and Meta-Analyses (PRISMA) flowchart [60] (Additional file 1: Figure S1).

\section{The estimate for gene-plasma total homocysteine association}

We used a pooled estimate of per-T allele standardized $\beta$ coefficient (0.158) of the effect of the MTHFR C677T polymorphism on the natural log-transformed plasma total homocysteine levels (beta ${ }_{\text {hcy/per }}$ T-allele) from a recent meta-analysis of genome-wide association studies comprising 44,147 individuals [2].

\section{Mendelian randomization analysis}

We calculated a Mendelian randomization estimate of the effect of the plasma total homocysteine levels on the risk of schizophrenia $\left(\mathrm{OR} \mathrm{scz}_{\mathrm{hcy}}\right)$ as $\log \mathrm{OR} \mathrm{scz}_{\mathrm{hcy}}=(\log$ OR scz/per T-allele)/ beta hcy/per T-allele, as in previous studies $[4,21]$. Log OR ${ }_{\text {scz/hcy }}$ is the $(\log )$ increase of schizophrenia risk by 1-standard deviation (SD) increase in the natural log-transformed plasma total homocysteine (plasma total homocysteine-schizophrenia association). Log OR scz/per T-allele is the $(\log )$ increase in schizophrenia risk per $\mathrm{T}$ allele of the MTHFR C677T polymorphism (gene-schizophrenia association). Beta hcy/per T-allele is the number of SD differences in the natural log-transformed plasma total homocysteine levels per the T allele (SD/ allele) (gene-plasma total homocysteine association).

\section{Results}

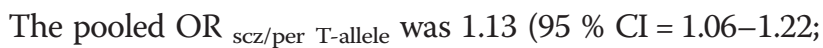
$p=5.9 \times 10^{-4}$ in the random-effects model) with significant heterogeneity $\left(\mathrm{I}^{2}=66.1 \% ; p<0.05\right.$; Fig. 1$)$. The funnel plot analysis indicated no evidence of publication bias in this meta-analysis $(p>0.05)$. By combining two pooled estimates, $\mathrm{OR}_{\mathrm{scz} / \mathrm{per}} \mathrm{T-allele}$ from a meta-analysis of 36 casecontrol studies and beta hcy/per T-allele from a meta-analysis of genome-wide association studies by van Meurs and colleagues [2], we found a significant effect of the plasma total homocysteine on schizophrenia risk in the Mendelian 


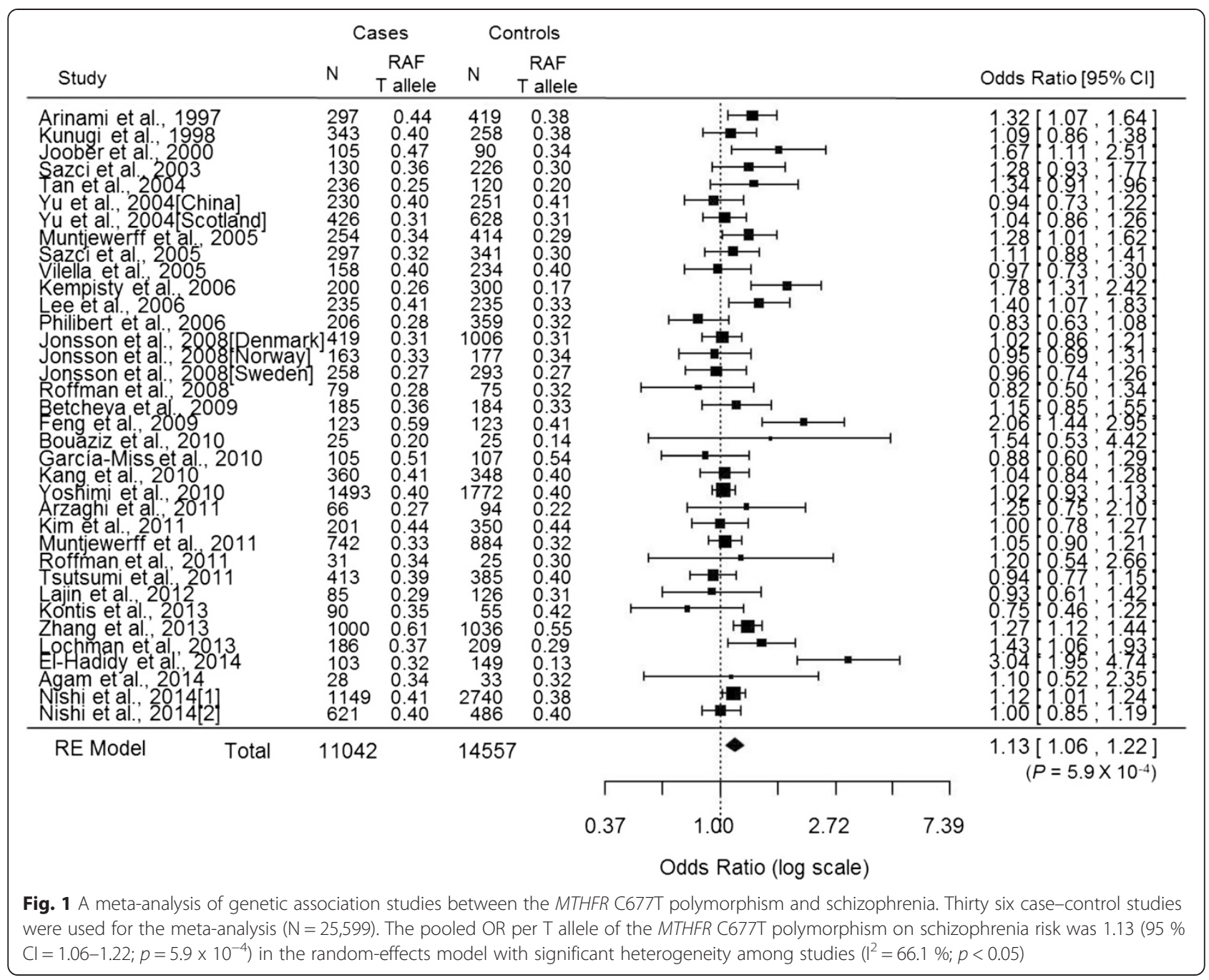

randomization analysis, representing an OR ${ }_{\text {scz/hcy }}$ of 2.15 (95\% CI $=1.39-3.32 ; p=5.3 \times 10^{-4}$ ) for schizophrenia per 1 -SD increase in the natural log-transformed plasma total homocysteine levels (Fig. 2).

\section{Discussion}

By conducting a Mendelian randomization approach, we demonstrated that increased plasma total homocysteine concentration levels may be causally associated with an increased risk of developing schizophrenia. Our finding is consistent with the result of our recent paper that used a Japanese cohort [4]. Our finding is also supported by a longitudinal study in which elevated maternal levels of homocysteine levels during the third trimester were found to increase the risk of schizophrenia in the offspring [61]. Furthermore, the benefits of homocysteine-reducing strategies in schizophrenia have been reported in previous studies with randomized, double-blind, and placebo-controlled designs. Levine et al. [62] reported an improvement in the clinical symptoms of the patients with schizophrenia and hyper-homocysteinemia (over $15 \mathrm{umol} / \mathrm{L}$ ) who were treated with folate, vitamin B12, and pyridoxine. Roffman et al. [63] reported an improvement in the negative symptoms of patients with schizophrenia who were treated with folate and vitamin B12 when several functional genetic variants were taken into account.

Hyper-homocysteine has also been observed in cardiovascular disease [64], and yet randomized trials have failed to demonstrate benefit of homocysteine-lowering intervention on cardiovascular outcomes [18, 65]. The discordant results from observational studies and randomized trials might be caused by the limited period of the randomized trials, the effects of aspirin and other antiplatelet drugs [66], confounding factors, or reverse causation. Several papers had not found evidence in support of a causal association between homocysteine and cardiovascular disease [2, 18].

There are some limitations to the present Mendelian randomization analysis. One is the number of genetic variants. We used one polymorphism as the instrumental 


\title{
MTHFR rs1801133 (T)
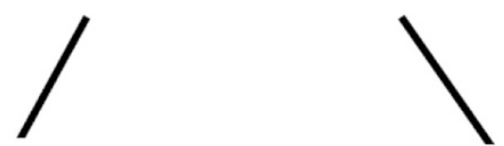

Number of SD differences in the natural logtransformed plasma total homocysteine levels per $\mathrm{T}$ allele

Beta $_{\text {hyy/per T-allele }}=0.158$ (SE: 0.007 )

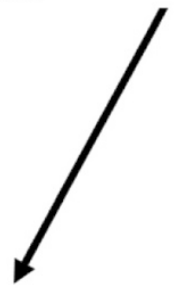

Per-T allele OR for schizophrenia (95\% Cl; $p$-value)

$\mathrm{OR}_{\text {scz/per T-allele }}=1.13\left(1.06-1.22 ; 5.9 \times 10^{-4}\right)$

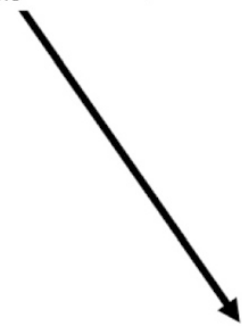

\section{Plasma total homocysteine - - $\rightarrow$ Schizophrenia risk}

\author{
MR estimate: OR for schizophrenia per 1-SD increase \\ in the natural log-transformed plasma total homocysteine levels \\ (95\% Cl; $p$-value) \\ $\mathrm{OR}_{\mathrm{scz} / \mathrm{hcy}}=2.15\left(1.39-3.32 ; 5.3 \times 10^{-4}\right)$
}

Fig. 2 Graphical representation of the Mendelian randomization approach. The risk estimate for the gene-schizophrenia association of the T allele of the MTHFR C677T polymorphism was obtained from the present meta-analysis of previous genetic association studies that cover a total of 25,599 individuals (11,042 cases and 14,557 controls). To establish the gene-homocysteine association, we took a pooled estimate of the effect of the MTHFR C677T polymorphism on the plasma total homocysteine levels from a recent meta-analysis of previous genome-wide association studies, including 44,147 individuals (van Meurs et al. [2]). From these two estimates, we calculated a Mendelian randomization estimate of the effect of the plasma total homocysteine levels on the risk of schizophrenia. This estimate represented the OR for schizophrenia risk per 1-SD increase in the log-transformed plasma total homocysteine levels

variable that affects the plasma total homocysteine concentrations. However, a recent meta-analysis of genome wide association studies of the plasma total homocysteine has identified several genetic variants [2]. Further replication studies will be needed using multiple genetic variants related to the plasma total homocysteine levels, because using multiple instruments increases the precision of the instrumental variable estimates [14]. The second is a reintroduced confounding through pleiotropy [12, 14, 15]. Pleiotropy is defined as the phenomenon in which a single locus affects two or more distinct phenotypic traits [67]. The MTHFR C677T polymorphism may directly influence more than one post-transcriptional process. The third is population stratification $[12,14,15]$. When we estimated both gene-schizophrenia association and gene-plasma total homocysteine association, we used a cohort that was composed of a mixed population. The fourth is a developmental compensation [12, 15]. During development, compensatory process may be generated that counter the phenotypic perturbation consequent on the genetic variant utilized as an instrument [15].

\section{Conclusions}

In summary, we provided evidence of a causal relationship between the plasma total homocysteine and schizophrenia by conducting a Mendelian randomization approach. However, our findings have to be interpreted with caution because of the limitations, such as pleiotropy and population stratification.

\section{Funding body agreements and policies}

This work was supported in part by Japan Science and Technology Agency, CREST and a Grant-in-Aid for Scientific Research from the Japanese Ministry of Education, Culture, Sports, Science and Technology (grant number 24791216 and 26860931), SENSHIN Medical Research Foundation, and the Research Group for Schizophrenia. 


\section{Additional file}

Additional file 1: Figure S1. A flowchart of study selection using a PRISMA checklist. The number of records identified through database searching was 234. After adjusting for duplicates, 113 studies were remained. By checking the titles, we excluded studies published in languages other than English (8 studies), review and case reports (13 studies), and studies using animal samples (4 studies). By reviewing abstracts, we excluded studies which were not case-control studies (34 studies), a study using cases without schizophrenia (1 study), and a study examining a different single-nucleotide polymorphisms (1 study). After these steps, 52 studies were remained. Of the 52 studies that were subjected to full-text inspection, we further excluded studies which did not contain original data (8 studies), studies which did not compare cases with controls ( 5 studies), a study which did not contain the details of samples (1 study), a study using cases without schizophrenia (1 study), and studies which were suspected overlapping of samples ( 5 studies). Finally, 32 papers, including 36 case-control studies, were remained.

\section{Competing interests}

The authors declare that they have no competing interests.

\section{Authors' contributions}

SN designed the study. SN and TO managed the research. MK and AN conducted the literature search. II, MK, and AT undertook the statistical analysis. SN wrote the first draft of this paper. All authors contributed to and have approved the final manuscript.

\section{Acknowledgments}

Mrs. Okada A assisted with the preparation of experiments and provided the data necessary for our analysis.

\section{Author details}

'Department of Psychiatry, Institute of Biomedical Sciences, Tokushima University Graduate School, 3-18-15, Kuramoto, Tokushima 770-8503, Japan. ${ }^{2}$ Department of Bioinformatics and Genomics, Graduate School of Medical Sciences, Kanazawa University, 13-1, Takawamachi, Kanazawa, Ishikawa 920-8640, Japan. ${ }^{3}$ Department of Human Genetics, Institute of Biomedical Sciences, Tokushima University Graduate School, 3-18-15, Kuramoto, Tokushima 770-8503, Japan.

Received: 11 November 2014 Accepted: 3 July 2015

Published online: 26 July 2015

\section{References}

1. Frosst P, Blom HJ, Milos R, Goyette P, Sheppard CA, Matthews RG, et al. A candidate genetic risk factor for vascular disease: a common mutation in methylenetetrahydrofolate reductase. Nat Genet. 1995;10:111-3.

2. van Meurs JB, Pare G, Schwartz SM, Hazra A, Tanaka T, Vermeulen SH, et al. Common genetic loci influencing plasma homocysteine concentrations and their effect on risk of coronary artery disease. Am J Clin Nutr. 2013;98: 668-76.

3. Muntjewerff JW, Kahn RS, Blom HJ, den Heijer M. Homocysteine, methylenetetrahydrofolate reductase and risk of schizophrenia: a meta-analysis. Mol Psychiatry. 2006;11:143-9.

4. Nishi A, Numata S, Tajima A, Kinoshita M, Kikuch IK, Shimodera S, et al. Meta-analyses of blood homocysteine levels for gender and genetic association studies of the MTHFR C677T polymorphism in schizophrenia. Schizophr Bull. 2014:40:1154-63

5. Davey SG, Ebrahim S. What can mendelian randomisation tell us about modifiable behavioural and environmental exposures? BMJ. 2005;330: 1076-9.

6. Refsum H, Smith AD, Ueland PM, Nexo E, Clarke R, McPartlin J, et al. Facts and recommendations about total homocysteine determinations: an expert opinion. Clin Chem. 2004:50:3-32

7. Hughes JR, Hatsukami DK, Mitchell JE, Dahlgren LA. Prevalence of smoking among psychiatric outpatients. Am J Psychiatry. 1986;143:993-7.

8. Patkar AA, Gopalakrishnan R, Lundy A, Leone FT, Certa KM, Weinstein SP. Relationship between tobacco smoking and positive and negative symptoms in schizophrenia. J Nerv Ment Dis. 2002;190:604-10.
9. Saedisomeolia A, Djalali M, Moghadam AM, Ramezankhani O, Najmi L. Folate and vitamin B12 status in schizophrenic patients. J Res Med Sci. 2011;16 Suppl 1:S437-41.

10. Song X, Fan X, Li X, Kennedy D, Pang L, Quan M, et al. Serum levels of BDNF, folate and homocysteine: in relation to hippocampal volume and psychopathology in drug naïve, first episode schizophrenia. Schizophr Res. 2014;159:51-5.

11. Davey SG, Ebrahim S. 'Mendelian randomization': can genetic epidemiology contribute to understanding environmental determinants of disease? Int J Epidemiol. 2003;32:1-22.

12. Lawlor DA, Harbord RM, Sterne JA, Timpson N, Davey SG. Mendelian randomization: using genes as instruments for making causal inferences in epidemiology. Stat Med. 2008;27:1133-63.

13. Bochud M, Rousson V. Usefulness of Mendelian randomization in observational epidemiology. Int J Environ Res Public Health. 2010;7:711-28.

14. Palmer TM, Lawlor DA, Harbord RM, Sheehan NA, Tobia JH, et al. Using multiple genetic variants as instrumental variables for modifiable risk factors. Stat Methods Med Res. 2012;21:223-42.

15. Davey SG, Hemani G. Mendelian randomization: genetic anchors for causal inference in epidemiological studies. Hum Mol Genet. 2014;23:R89-98.

16. Taylor AE, Davies NM, Ware JJ, VanderWeele T, Smith GD, Munafò MR. Mendelian randomization in health research: using appropriate genetic variants and avoiding biased estimates. Econ Hum Biol. 2014;13:99-106.

17. Thanassoulis G. Mendelian randomization: how genetics is pushing the boundaries of epidemiology to identify new causes of heart disease. Can J Cardiol. 2013;29:30-6.

18. Clarke R, Bennett DA, Parish S, Verhoef P, Dötsch-Klerk M, Lathrop M, et al. MTHFR Studies Collaborative Group. Homocysteine and coronary heart disease: meta-analysis of MTHFR case-control studies, avoiding publication bias. PLoS Med. 2012;9:e1001177.

19. Voight BF, Peloso GM, Orho-Melander M, Frikke-Schmidt R, Barbalic M, Jensen MK, et al. Plasma HDL cholesterol and risk of myocardial infarction: a mendelian randomisation study. Lancet. 2012;380:572-80.

20. Palmer TM, Nordestgaard BG, Benn M, Tybjærg-Hansen A, Davey SG, Lawlor DA, et al. Association of plasma uric acid with ischaemic heart disease and blood pressure: mendelian randomisation analysis of two large cohorts. BMJ. 2013;347:f4262.

21. Pichler I, Del Grec MF, Gögele M, Lill CM, Bertram L, Do CB, et al. Serum iron levels and the risk of Parkinson disease: a Mendelian randomization study. PLoS Med. 2013;10:e1001462.

22. Yaghootkar H, Lamina C, Scott RA, Dastani Z, Hivert MF, Warren LL, et al. Mendelian randomization studies do not support a causal role for reduced circulating adiponectin levels in insulin resistance and type 2 diabetes. Diabetes. 2013;62:3589-98.

23. Holmes MV, Asselbergs FW, Palmer TM, Drenos F, Lanktree MB, Nelson CP et al. Mendelian randomization of blood lipids for coronary heart disease. Eur Heart J. 2014. [Epub ahead of print].

24. Holmes MV, Dale CE, Zuccolo L, Silverwood RJ, Guo Y, Ye Z, et al. Association between alcohol and cardiovascular disease: Mendelian randomisation analysis based on individual participant data. BMJ. 2014;349:94164.

25. Holmes MV, Lange LA, Palmer T, Lanktree MB, North KE, Almoguera B, et al. Causal effects of body mass index on cardiometabolic traits and events: a Mendelian randomization analysis. Am J Hum Genet. 2014;94:198-208.

26. Soave D, Miller MR, Keenan K, Li W, Gong J, Ip W, et al. Evidence for a causal relationship between early exocrine pancreatic disease and cystic fibrosis-related diabetes: a Mendelian randomization study. Diabetes. 2014:63:2114-9.

27. Allen NC, Bagade S, McQueen MB, loannidis JP, Kavvoura FK, Khoury MJ, et al. Systematic meta-analyses and field synopsis of genetic association studies in schizophrenia: the SzGene database. Nat Genet. 2008;40:827-34.

28. Egger M, Davey SG, Schneider M, Minder C. Bias in meta-analysis detected by a simple, graphical test. BMJ. 1997;315:629-34.

29. Arinami T, Yamada N, Yamakawa-Kobayashi K, Hamaguch $I H$, Toru M. Methylenetetrahydrofolate reductase variant and schizophrenia/ depression. Am J Med Genet. 1997;74:526-8.

30. Kunugi H, Fukuda R, Hattori M, Kato T, Tatsumi M, Sakai T, et al. C677T polymorphism in methylenetetrahydrofolate reductase gene and psychoses. Mol Psychiatry. 1998;3:435-7.

31. Joober R, Benkelfat C, Lal S, Bloom D, Labelle A, Lalonde P, et al. Association between the methylenetetrahydrofolate reductase $677 \mathrm{C}>\mathrm{T}$ missense mutation and schizophrenia. Mol Psychiatry. 2000;5:323-6. 
32. Sazci A, Ergül E, Güzelhan $Y$, Kaya G, Kara I. Methylenetetrahydrofolate reductase gene polymorphisms in patients with schizophrenia. Brain Res Mol Brain Res. 2003;117:104-7.

33. Tan EC, Chong SA, Lim LC, Chan AO, Teo YY, Tan CH, et al. Genetic analysis of the thermolabile methylenetetrahydrofolate reductase variant in schizophrenia and mood disorders. Psychiatr Genet. 2004;14:227-31.

34. Yu L, Li T, Robertson Z, Dean J, Gu NF, Feng GY, et al. No association between polymorphisms of methylenetetrahydrofolate reductase gene and schizophrenia in both Chinese and Scottish populations. Mol Psychiatry. 2004:9:1063-5.

35. Muntjewerff JW, Hoogendoorn ML, Kahn RS, Sinke RJ, Den Heijer M, Kluijtmans LA, et al. Hyperhomocysteinemia, methylenetetrahydrofolate reductase 677TT genotype, and the risk for schizophrenia: a Dutch population based case-control study. Am J Med Genet B Neuropsychiatr Genet. 2005;135B:69-72.

36. Sazci A, Ergul E, Kucukali I, Kara I, Kaya G. Association of the C677T and A1298C polymorphisms of methylenetetrahydrofolate reductase gene with schizophrenia: association is significant in men but not in women. Prog Neuropsychopharmacol Biol Psychiatry. 2005;29:1113-23.

37. Vilella E, Virgos C, Murphy M, Martorell L, Valero J, Simó JM, et al. Further evidence that hyperhomocysteinemia and methylenetetrahydrofolate reductase C677T and A1289C polymorphisms are not risk factors for schizophrenia. Prog Neuropsychopharmacol Biol Psychiatry. 2005;29:1169-74

38. Kempisty B, Mostowska A, Górska I, Łuczak M, Czerski P, Szczepankiewicz A, et al. Association of $677 C>$ T polymorphism of methylenetetrahydrofolate reductase (MTHFR) gene with bipolar disorder and schizophrenia. Neurosci Lett. 2006;400:267-71.

39. Lee YS, Han DH, Jeon CM, Lyoo IK, Na C, Chae SL, et al. Serum homocysteine, folate level and methylenetetrahydrofolate reductase 677 1298 gene polymorphism in Korean schizophrenic patients. Neuroreport. 2006;17:743-6.

40. Philibert R, Gunter T, Hollenbeck N, Adams WJ, Bohle P, Packer H, et al. No association of the C677T methylenetetrahydrofolate reductase polymorphism with schizophrenia. Psychiatr Genet. 2006;16:221-3.

41. Jönsson EG, Larsson $K$, Vares M, Hansen T, Wang AG, Djurovic S, et al. Two methylenetetrahydrofolate reductase gene (MTHFR) polymorphisms, schizophrenia and bipolar disorder: an association study. Am J Med Genet B Neuropsychiatr Genet. 2008;147B:976-82.

42. Roffman JL, Gollub RL, Calhoun VD, Wassin TH, Weiss AP, Ho BC, et al. MTHFR 677C > T genotype disrupts prefrontal function in schizophrenia through an interaction with COMT 158Val > Met. Proc Natl Acad Sci U S A. 2008;105:17573-8.

43. Betcheva ET, Mushiroda T, Takahashi A, Kubo M, Karachanak SK, Zaharieva IT, et al. Case-control association study of 59 candidate genes reveals the DRD2 SNP rs6277 (C957T) as the only susceptibility factor for schizophrenia in the Bulgarian population. J Hum Genet. 2009;54:98-107.

44. Feng LG, Song ZW, Xin F, Hu J. Association of plasma homocysteine and methylenetetrahydrofolate reductase C677T gene variant with schizophrenia: A Chinese Han population-based case-control study. Psychiatry Res. 2009;168:205-8.

45. Bouaziz N, Ayedi I, Sidhom O, Kallel A, Rafrafi R, Jomaa R, et al. Plasma homocysteine in schizophrenia: determinants and clinical correlations in Tunisian patients free from antipsychotics. Psychiatry Res. 2010;2010(179):24-9.

46. García-Miss Mdel R, Pérez-Mutul J, López-Canul B, Solís-Rodríguez F, Puga-Machado L, Oxté-Cabrera A, et al. Folate, homocysteine, interleukin-6, and tumor necrosis factor alfa levels, but not the methylenetetrahydrofolate reductase C677T polymorphism, are risk factors for schizophrenia. J Psychiatr Res. 2010;44:441-6.

47. Kang HJ, Choe BM, Kim SH, Son SR, Lee KM, Kim BG, et al. No Association Between Functional Polymorphisms in COMT and MTHFR and Schizophrenia Risk in Korean Population. Epidemiol Health. 2010;32:e2010011.

48. Yoshimi A, Aleksic B, Kawamura Y, Takahashi N, Yamada S, Usui H, et al. Gene-wide association study between the methylenetetrahydrofolate reductase gene (MTHFR) and schizophrenia in the Japanese population, with an updated meta-analysis on currently available data. Schizophr Res. 2010;124:216-22.

49. Arzaghi SM, Hossein-Nezhad A, Shariat SV, Ghodsipour A, Shams J, Larijani B. C677T Methylenetetrahydrofolate Reductase (MTHFR) Gene Polymorphism in Schizophrenia and Bipolar Disorder: An Association Study in Iranian Population. Iran J Psychiatry. 2011;6:1-6.
50. Kim SG, Song JY, Joo EJ, Jeong SH, Kim SH, Lee KY, et al. No association of functional polymorphisms in methlylenetetrahydrofolate reductase and the risk and minor physical anomalies of schizophrenia in Korean population. J Korean Med Sci. 2011;26:1356-163.

51. Muntjewerff JW, Ophoff RA, Buizer-Voskamp JE, Strengman E, den Heijer M, GROUP Consortium. Effects of season of birth and a common MTHFR gene variant on the risk of schizophrenia. Eur Neuropsychopharmacol. 2011:21:300-5.

52. Tsutsumi A, Glatt SJ, Kanazawa T, Kawashige S, Uenishi H, Hokyo A, et al. The genetic validation of heterogeneity in schizophrenia. Behav Brain Funct. 2011;7:43.

53. Roffman JL, Nitenson AZ, Agam $Y$, Isom M, Friedman JS, Dyckman KA, et al A hypomethylating variant of MTHFR, 677C $>$ T, blunts the neural response to errors in patients with schizophrenia and healthy individuals. PLoS One. 2011:6:e25253.

54. Lajin B, Alhaj Sakur A, Michati R, Alachkar A. Association between MTHFR C677T and A1298C, and MTRR A66G polymorphisms and susceptibility to schizophrenia in a Syrian study cohort. Asian J Psychiatr. 2012;5:144-9.

55. El-Hadidy MA, Abdeen HM, Abd El-Aziz SM, Al-Harrass M. C677T Methylenetetrahydrofolate reductase gene polymorphism in schizophrenia and bipolar disorder. Psychiatr Genet. 2013. [Epub ahead of print].

56. Kontis D, Theochari E, Fryssira H, Kleisas S, Sofocleous C, Andreopoulou A, et al. COMT and MTHFR polymorphisms interaction on cognition in schizophrenia: an exploratory study. Neurosci Lett. 2013;537:17-22.

57. Zhang Y, Yan H, Tian L, Wang F, Lu T, Wang L, et al. Association of MTHFR C677T polymorphism with schizophrenia and its effect on episodic memory and gray matter density in patients. Behav Brain Res. 2013;243:146-52.

58. Lochman J, Plesník J, Janout V, Povová J, Míšek I, Dvořáková D, et al. Interactive effect of MTHFR and ADRA2A gene polymorphisms on pathogenesis of schizophrenia. Neuro Endocrinol Lett. 2013;34:792-7.

59. Agam Y, Vangel M, Roffman JL, Gallagher PJ, Chaponis J, Haddad S, et al. Dissociable genetic contributions to error processing: a multimodal neuroimaging study. PLoS One. 2014;9:e101784.

60. Liberati A, Altman DG, Tetzlaff J, Mulrow C, Gøtzsche PC, loannidis JP, et al. The PRISMA statement for reporting systematic reviews and meta-analyses of studies that evaluate healthcare interventions: explanation and elaboration. BMJ. 2009;339:b2700.

61. Brown AS, Bottiglieri T, Schaefer CA, Quesenberry Jr CP, Liu L, Bresnahan M, et al. Elevated prenatal homocysteine levels as a risk factor for schizophrenia. Arch Gen Psychiatry. 2007;64:31-9.

62. Levine J, Stahl Z, Sela BA, Ruderman V, Shumaico O, Babushkin I, et al, Homocysteine-reducing strategies improve symptoms in chronic schizophrenic patients with hyperhomocysteinemia. Biol Psychiatry. 2006;60:265-9.

63. Roffman JL, Lamberti JS, Achtyes E, Macklin EA, Galendez GC, Raeke LH, et al. Randomized multicenter investigation of folate plus vitamin B12 supplementation in schizophrenia. JAMA Psychiatry. 2013;70:481-9.

64. Wald DS, Law M, Morris JK. Homocysteine and cardiovascular disease: evidence on causality from a meta-analysis. BMJ. 2002;325:1202.

65. Martí-Carvajal AJ, Solà I, Lathyris D, Karakitsiou D-E, Simancas-Racines D. Homocysteine-lowering interventions for preventing cardiovascular events. Cochrane Database Syst Rev. 2013;1:CD006612.

66. Wald DS, Morris JK, Wald NJ. Reconciling the evidence on serum homocysteine and ischaemic heart disease: a meta-analysis. PLoS One. 2011;6:e16473.

67. Stearns FW. One hundred years of pleiotropy: a retrospective. Genetics. 2010;186:767-73. 